\title{
Estudio comparativo de calidad higiénico- sanitaria, fisicoquímica y microbiológica de leche bovina en el sureste mexicano
}

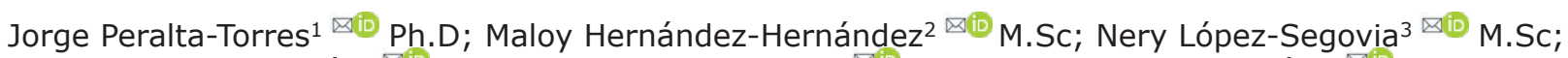

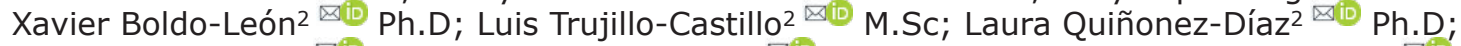 \\ David Betancur-Ancona ${ }^{\star} \bowtie(\mathbb{0})$ Ph.D; Jorge Ble-Castillo ${ }^{凶}$ Ph.D; Viridiana Olvera-Hernández ${ }^{2 *} \bowtie \mathbb{C}$ Ph.D.
}

\begin{abstract}
${ }^{1}$ Universidad Juárez Autónoma de Tabasco, División Académica de Ciencias Agropecuarias. Villahermosa, Tabasco, México. Universidad Juárez Autónoma de Tabasco, División Académica de Ciencias de la Salud. Villahermosa, Tabasco, México. 3Universidad Mundo Maya, Campus Villahermosa. Villahermosa, Tabasco, México.

${ }^{4}$ Universidad Autónoma de Yucatán, Facultad de Ingeniería Química. Mérida, Yucatán, México.

*Correspondencia: viryolvera11@gmail.com
\end{abstract}

Recibido: Julio 2020; Aceptado: Enero 2021; Publicado: Mayo 2021.

\section{RESUMEN}

Objetivo. Evaluar la calidad higiénico-sanitaria, fisicoquímica y microbiológica de leche cruda bovina destinada a la venta, producida en un establo familiar y en tres mercados públicos del estado de Tabasco. Materiales y métodos. La calidad higiénico-sanitaria se determinó de acuerdo con la información general del predio, instalaciones, proceso de ordeño, limpieza y desinfección. La calidad fisicoquímica se determinó evaluando proteínas totales, caseína, grasa butírica, lactosa, sólidos no grasos y densidad. La calidad microbiológica fue determinada mediante la acidez titulable, prueba de alcohol, contenido de células somáticas, potencial de óxido-reducción, materia extraña, inhibidores bacterianos y bacterias mesofílicas aerobias. Resultados. La leche producida en el establo familiar, fue evaluada con la máxima calidad fisicoquímica y microbiológica en referencia a los estándares que evalúa la normatividad oficial mexicana establecidas en México por el Consejo para el fomento de la calidad de la leche y sus derivados, A. C. En cambio, la leche en los tres mercados públicos se consideró de rechazo, indicando posible contaminación durante los procesos de ordeña, así como en el manejo y transporte hacia los mercados públicos. Conclusiones. Las muestras de leche provenientes de los mercados públicos se consideraron no aptas para consumo humano ni para elaboración de subproductos.

Palabras clave: Bacterias mesofílicas; calidad de leche; células somáticas; mastitis; nutrición humana; proteína (Fuente: DeCS).

\section{ABSTRACT}

Objective. Evaluate the hygienic-sanitary, physicochemical and microbiological quality of bovine milk for sale, produced in a family stable and in three public markets in Tabasco state. Materials and methods. The hygienic-sanitary quality was determined according to general information of the farm, facilities, milking process, cleaning and disinfection. Physicochemical quality was determined sanitaria, fisicoquímica y microbiológica de leche bovina en el sureste mexicano. Rev MVZ Córdoba. 2021; 26(3):e2106. https://doi.org/10.21897/rmvz.2106 
by evaluating total proteins, casein, butyric fat, lactose, non-fatty solids and density. Microbiological quality was determined by titratable acidity, alcohol test, somatic cell content, oxide-reduction potential, foreign matter, bacterial inhibitors, and aerobic mesophilic bacteria. Results. The milk produced in the family stable was evaluated with the highest physicochemical and microbiological quality, in reference to the standards evaluated by the official Mexican regulations established in Mexico by the Council for the promotion of the quality of milk and its derivatives, A. C. Instead, milk in three public markets, it was considered as rejection, indicating possible contamination during milking processes, as well as handling and transport to public markets. Conclusions. Milk samples from public markets were considered not suitable for human consumption or for the production of by-products.

Keywords: Human nutrition; mastitis; mesophilic bacteria; milk quality; protein; somatic cells (Source: DeCS).

\section{INTRODUCCIÓN}

La importancia alimentaria de la leche de vaca para la nutrición humana reside en que se considera un alimento completo al aportar elementos tales como carbohidratos, lípidos, proteínas y minerales; por mencionar, calcio, cloro, cobre, fósforo, hierro, magnesio, potasio, sodio, yodo y zinc. También contiene vitaminas como A, B6, B12, C, D, E, tiamina, riboflavina y folatos. La composición de sólidos totales en este alimento, principalmente proteína y grasa, contribuyen a la elaboración de diversos productos lácteos tales como: quesos, cremas y mantequilla, sometidos a procesos tecnológicos (1). Siendo los principales responsables del flavor de estos, los aminoácidos y los ácidos grasos de cadena corta presentes (2). Sin embargo, esta composición puede estar influenciada por factores como la raza, la genética, la alimentación, el medio ambiente y el manejo de las vacas (3).

De acuerdo a la Organización de las Naciones Unidas para la Alimentación y la Agricultura, la producción lechera mundial para el año 2017 registró más de 652 millones de toneladas (4). Para 2019, el Servicio de Información Agroalimentaria y Pesquera reportó para México, una producción de 12380 t de leche. Se considera que la producción bovina de doble propósito en los países tropicales, es en donde mayor leche se obtiene. En México, más del 30\% del producto lácteo, proviene de sistemas tropicales de doble propósito (5). Al respecto, la producción registrada en 2019 en el estado de Tabasco, México, fue de 103894 litros, siendo esta una zona tropical del país, es de interés conocer la calidad de la leche que se produce y distribuye en algunos mercados de esta entidad, especialmente porque la leche es un producto que se considera alimento básico en la nutrición humana.
La leche al ser considerada alimento básico durante todas las etapas de la vida en el ser humano, demanda de forma indispensable que la industria solicite a los productores, requisitos para establecer su calidad de acuerdo con estándares higiénicos-sanitarios, fisicoquímicos y microbiológicos (6). La determinación de contaminantes, tales como materia extraña, formaldehídos, oxidantes, derivados clorados, entre otros, que se encuentran presentes en la leche cruda bovina es un tema de importancia para la salud pública a nivel mundial, ya que, junto con sus derivados, constituyen productos de consumo masivo, destinándose aproximadamente el $75 \%$ de la producción para el consumo humano (7).

Uno de los factores principales para la obtención de una leche de calidad es la higiene, la cual, debe estar presente durante todo el proceso de obtención: pre-ordeño, ordeño y post-ordeño. Las prácticas adecuadas de higiene se deben incluir en el personal, el manejo de animales, de equipos e instalaciones, esto con la finalidad de disminuir el riesgo de contaminación con microorganismos patógenos, lo cual se asocia a la ausencia de mastitis considerando así una leche apta para consumo humano (8). Una de las causas que ejerce influencia extremamente perjudicial sobre la composición y las características físico-químicas de la leche es la mastitis, acompañada por el aumento del conteo de células somáticas (CS). Con el aumento de CS, la composición de la leche, la actividad enzimática, el tiempo de coagulación, la productividad y la calidad de los derivados lácteos son influenciados negativamente. Altos niveles bacterianos y de CS, también afectan significativamente los procesos de producción de leche pasteurizada y queso, se acorta la vida de estos productos reduciendo la aceptación 
del consumidor, generados por la reducción de lactosa, caseína, grasa y concentración de proteínas en la leche (1). El almacenamiento post-ordeño y el transporte a los puntos de venta, son factores que también afectan en la contaminación y calidad de la leche tanto para consumo directo, como para la elaboración de productos derivados (8).

Por lo anterior, el objetivo del presente estudio fue evaluar la calidad higiénico-sanitaria, fisicoquímica y microbiológica de la leche cruda de vaca, producida y distribuida en diferentes establecimientos dedicados a su venta, en el estado de Tabasco, México.

\section{MATERIALES Y MÉTODOS}

Ubicación geográfica de las unidades de producción. El estudio se realizó en cuatro establecimientos del estado de Tabasco: un establo familiar (EF) y tres mercados públicos. El EF se ubicó en el municipio de Cunduacán, Tabasco, México (longitud -93.180556 y latitud 18.146111), a una altitud de $20 \mathrm{msnm}$. Con clima cálido-húmedo, Iluvias en verano, $28.7^{\circ} \mathrm{C}$ y $1940.6 \mathrm{~mm}$ de temperatura y precipitación promedio anual, respectivamente.

Los tres mercados públicos estuvieron ubicados en Villahermosa, Tabasco, México: Mercado Pino Suárez (longitud -93.3833 y latitud 18.3542), Mercado del tianguis campesino (longitud -92.9182424 y latitud 17.998573) y Mercado de Tamulté (longitud $-92.9596527,597$ y latitud 17.9713493) (MP, MC y MT, respectivamente), en los cuales se registró la venta de leche cruda de vaca para consumo humano.

Características del muestreo. El muestreo de leche, comprendió un periodo de 28 días en época de nortes (diciembre-enero), tanto para los muestreos en el EF, como en los mercados públicos. Todas las muestras fueron recolectadas en un frasco estéril de vidrio libre de fenol, tres veces por semana, durante este período, y se transportaron al laboratorio de Bromatología de la División Académica de Ciencias de la salud (DACS) de la Universidad Juárez Autónoma de Tabasco (UJAT), en una hielera con refrigerante, manteniendo una temperatura de $4^{\circ} \mathrm{C}$.

Muestreo en el establo familiar. El muestreo se realizó en 35 vacas con producción promedio de $8.6 \pm 1.8 \mathrm{~kg}$ de leche/vaca/día bajo un sistema semi-intensivo con tipo de ordeño mecánico, una vez al día en horario matutino (04:00-06:30 h), en el cual participaron tres trabajadores. El muestreo se realizó una vez terminado el ordeño. Los genotipos fueron cruzas de: Holstein $\times$ Gyr y Suizo pardo $\times$ Gyr. El sistema de ordeño estuvo integrado con tanque enfriador con capacidad de almacenamiento de $1000 \mathrm{~L}$ y mantenimiento de la leche a $4^{\circ} \mathrm{C}$. Dicho EF incluyó actividad de venta de leche cruda para consumo humano y producción de queso artesanal.

Características del muestreo en los mercados. El muestreo se realizó en los mercados públicos MP, MC y MT, en los que se vendía leche cruda de vaca para consumo humano. Dichos muestreos fueron realizados simultáneamente con el EF.

Reactivos utilizados. Hidróxido de sodio, lactosa monohidrato, formaldehído, ácido fosfórico, sulfato de sodio anhídrido, cloruro de benzalconio, xileno, etanol, agar extracto de levadura, sal disódica de ácido cromotropico, ácido clorhídrico, almidón, glicerina, yoduro de potasio, azul de metileno, ácido acético, disolución amortiguadora de fosfatos (PBS) ajustada a pH 7.4, rojo de metilo, ácido sulfúrico, zinc, acetato de zinc dihidrato, ácido bórico, ácido benzoico, éter de petróleo, sulfato de cobre en solución, sulfato de potasio, potasio, tartrato de sodio, tiosulfato de sodio y cloroformo fueron adquiridos de Merck ${ }^{\circledR}$ Millipore, Alemania.

Calidad higiénico-sanitaria. Para realizar la evaluación de la calidad higiénico-sanitaria en el EF, se aplicó un cuestionario previamente descrito (9), donde se tomó información general del predio, referente a sus instalaciones y aspectos sobre el proceso del ordeño, limpieza y desinfección. En los mercados públicos se realizó la adquisición de datos mediante un tipo encuesta aplicado a los locatarios sobre las especificaciones sanitarias de procedencia del producto.

Tanto la evaluación y los criterios de la calidad físico-química, como la calidad microbiológica, se llevaron a cabo de acuerdo a las Normas establecidas en México por el Consejo para el fomento de la calidad de la leche y sus derivados, A.C. (COFOCALEC), las cuales están basadas en los métodos de prueba establecidos en el AOAC internacional. Dichas pruebas se describen a continuación.

Calidad físico-química. A las muestras de leche se les realizaron todas las determinaciones por 
triplicado. Estas fueron: las proteínas totales, la caseína, la grasa butírica, la lactosa, los sólidos no grasos y la densidad (6). Los métodos utilizados se describen a continuación:

Proteínas totales. Las muestras fueron digeridas en un equipo Kjeldahl Labconco ${ }^{\circledR}$ (EE. UU.) de 410 a $430^{\circ} \mathrm{C}$. Al término de la digestión, se sometieron a enfriamiento a temperatura ambiente en condiciones de laboratorio $\left(24^{\circ} \mathrm{C}\right)$, y se destilaron hasta que se obtuvo un volumen de $150 \mathrm{~mL}$. El destilado se tituló con $\mathrm{HCl} 0.1 \mathrm{~N}$ utilizando indicador Wesslow. El porcentaje de proteínas fue expresado en $\mathrm{g} / \mathrm{L}$.

Caseína. La caseína se precipitó colocando agua destilada en las muestras, posteriormente se agregó solución de ácido acético hasta llegar a un $\mathrm{pH}$ de 4.6 mediante un medidor de $\mathrm{pH}$ (SM$3 \mathrm{BW}{ }^{\circledR}$, Science med, Finlandia). Posteriormente se llevó a cabo el proceso de cuantificación de proteínas totales. Los resultados fueron expresados en $\mathrm{g} / \mathrm{L}$.

Grasa butírica. Las muestras se deshidrataron en una estufa de secado (ED-23 ${ }^{\circledR}$, Binder, Alemania). Posteriormente, se colocaron en un extractor de grasa (GL-45 ${ }^{\circledR}$, Labconco, EE.UU.) bajo extracción continua. Los resultados fueron expresados en $\mathrm{g} / \mathrm{L}$.

Lactosa. Se determinó el porcentaje de reductores directos en lactosa utilizando una solución de ferrocianuro de potasio y acetato de zinc. Los resultados fueron expresados en $\mathrm{g} / \mathrm{L}$.

Sólidos no grasos. Una vez determinado el contenido de sólidos totales de la leche y el contenido de grasa, se determinó el contenido de solidos no grasos por cálculo, ya que están formados por lactosa, proteínas y sales minerales. Los resultados de solidos no grasos fueron expresados en $\mathrm{g} / \mathrm{L}$.

Densidad. Las muestras se calentaron a $40^{\circ} \mathrm{C}$ en un baño María (DSB-1000D ${ }^{\circledR}$, digisystem lab instruments, Taiwán) por 5 min, posteriormente se llevaron a una temperatura de $20^{\circ} \mathrm{C}$ para introducir el termo-lactodensímetro de Quevenne (71384000 ${ }^{\circledR}$, Nahita, Japón). Los resultados fueron expresados en $\mathrm{g} / \mathrm{mL}$.

Calidad microbiológica. Todas las determinaciones se realizaron por triplicado. Las determinaciones realizadas fueron: la acidez titulable, la prueba de alcohol (termoestabilidad), el contenido de CS, la determinación del potencial de óxido-reducción de la leche (reductasa), la materia extraña, los inhibidores bacterianos y el conteo total de bacterias mesofílicas (6).

Acidez titulable. Se midió por titulación alcalimétrica con hidróxido de sodio $0.1 \mathrm{~N}$ utilizando una solución de fenolftaleína $(1 \% \mathrm{v} / \mathrm{v}$, en etanol) como indicador, hasta detectar $\mathrm{pH}$ de 8.3 mediante un medidor de $\mathrm{pH}\left(23-\mathrm{F}^{\circledR}\right.$, HANNA, Alemania). Los resultados fueron expresados en $\mathrm{g} / \mathrm{L}$.

Termoestabilidad (prueba de alcohol). A la muestra de leche se le adicionaron $2 \mathrm{~mL}$ de alcohol etílico al $72 \%$, posteriormente se agitó y se observó para verificar la formación de grumos o coágulos.

Contenido de células somáticas. Se preparó un frotis sobre un portaobjetos, las CS se tiñeron y se observaron al microscopio (BX $41{ }^{\circledR}$, Olympus, Japón) a 400X. El número de CS se determinó mediante conteo directo en cámara de Neubauer empleando la tinción modificada de Newman-Lampert. El resultado se expresó como el número de $\mathrm{CS} / \mathrm{mL}$.

Potencial de óxido-reducción de la leche (reductasa). La muestra de leche se colocó dentro de un tubo y se le agregó azul de metileno, para que se mezclara con este colorante. Se incubó a $37^{\circ} \mathrm{C}$ en un baño maría (DSB1000D ${ }^{\circledR}$, DS Lab Digital Taiwán), registrando el tiempo hasta la desaparición del color azul. El resultado se expresó de acuerdo con el número estimado de bacterias por $\mathrm{mL}$.

Presencia de materia extraña. Mediante un sistema de filtración se procesó toda la muestra, con ayuda una bomba de vacío (FE-1500L ${ }^{\circledR}$, Felisa, México). Se realizó la búsqueda de material extraño en un microscopio binocular (BX-41 ${ }^{\circledR}$, Olympus, Japón).

Inhibidores bacterianos. Se realizó evaluando la presencia/ausencia de formaldehidos, oxidantes, sales cuaternarias de amonio y derivados clorados.

Bacterias mesofílicas aeróbias. Se realizaron diluciones $10-1,10-2,10-3$ y 10-4 de la muestra y se sembraron por duplicado con la técnica de espatulado en agar cuenta estándar (BD, Bioxon) dentro de una campana de seguridad biológica (Clase II A/B3, Forma Scientific, EE.UU.). La incubación se realizó en una estufa bacteriológica (EC-41 ${ }^{\circledR}$, Ríos Rocha, México) a una temperatura 
de $35 \pm 2{ }^{\circ} \mathrm{C}$ por $48 \pm 2 \mathrm{~h}$. El conteo se llevó a cabo con ayuda de un contador de colonias (CM1$300^{\circledR}$, Figursa, México). El número de colonias se expresó como unidades formadoras de colonia por $\mathrm{mL}(\mathrm{UFC} / \mathrm{mL})$.

Análisis de los resultados. Se utilizó un diseño completamente al azar, los tratamientos fueron los diferentes sitios de muestreo y las variables de respuesta fueron las evaluaciones realizadas para determinar la calidad higiénico-sanitaria, físico-química y microbiológica de la leche. El análisis de los datos se llevó a cabo mediante una prueba ANOVA de una vía, utilizando el paquete Statgraphics versión 16. La comparación de medias se realizó utilizando una prueba de Tukey siendo significativos los resultados con $\mathrm{p}<0.05$ ( $95 \%$ de confianza).

\section{RESULTADOS}

La calidad higiénico-sanitaria contempló evaluación durante las etapas de pre-ordeño, ordeño y post-ordeño; así como la limpieza, desinfección y manejo de las instalaciones. A este respecto, la evaluación de la calidad higiénico-sanitaria en el $E F$, se cumplió hasta en un $85 \%$. Las actividades que no se cumplieron, fueron las correspondientes al manejo en las instalaciones como, por ejemplo, las paredes del lugar no estaban pintadas con un color claro, hubo presencia de fauna (gallinas) dentro de la sala de ordeña, el agua no se potabilizó utilizando una concentración establecida de cloro ( $2 \mathrm{mg} / \mathrm{L})$, además, no existieron registros de llevarse a cabo muestreos fisicoquímicos de la leche con período anual y muestreos microbiológicos semestralmente.
Al interrogar a los dueños de los establecimientos en los mercados, para indagar el conocimiento sobre el origen de la leche, el $100 \%$ refirió no conocer las medidas higiénico-sanitarias que se llevaron a cabo durante el proceso de recolección del producto lácteo, así como su transporte hasta el punto de venta. En todos los casos, el transporte de la leche es en método caliente y no en tanque de enfriamiento, sin embargo, no existe manera de asegurar que la leche no fue almacenada previamente o que sea entregada el mismo día de la ordeña.

De acuerdo a la normatividad mexicana establecida por el Consejo para el fomento de la calidad de la leche y sus derivados, A.C., la calidad fisicoquímica de la leche por el contenido de grasa butírica y de proteínas totales, puede ser evaluada de "Clase A, $B$ o C", entendiéndose que la Clase A es la máxima calidad. De acuerdo con el contenido de caseína, lactosa, sólidos no grasos y densidad, el criterio de clasificación es como "aceptada" o "de rechazo".

La leche proveniente de la FM fue clasificada en "Clase A" por el contenido de grasa butírica y de proteínas totales; de acuerdo con el contenido de caseína, lactosa, sólidos no grasos y densidad, se clasificó como "aceptada". Sin embargo, las muestras obtenidas de los tres diferentes mercados públicos (MC, MP y MT) tuvieron una clasificación "de rechazo" (Tabla 1).

Por el contenido de grasa butírica, las muestras de leche analizadas en el MT fueron clasificadas como "Clase B". Las muestras analizadas en el MC se clasificaron como "Clase C", de acuerdo al contenido de proteínas totales presentes. Destaca el hecho de que, en el MT se observaron los valores más bajos $(\mathrm{p}<0.05)$ de grasa butírica y de sólidos no grasos. $Y$ en el $\mathrm{MC}$ se observaron los valores más bajos $(p<0.05)$ de proteínas totales, caseína y lactosa.

Tabla 1. Evaluación de la calidad fisicoquímica de leche obtenida de un establo familiar y de tres mercados públicos en el estado de Tabasco.

\begin{tabular}{|c|c|c|c|c|c|c|}
\hline \multirow{2}{*}{ Est } & \multicolumn{6}{|c|}{ Parámetros y evaluación de la calidad fisicoquímica de leche } \\
\hline & $\mathbf{G B} \mathbf{g} / \mathbf{L}$ & PT $\mathbf{g} / \mathbf{L}$ & Cas $\mathbf{g} / \mathbf{L}$ & Lac g/L & SNG g/L & Den $\mathbf{g} / \mathbf{m L}$ \\
\hline $\mathrm{EF}$ & $\begin{array}{c}34.10 \pm 0.75 \\
\text { Clase } A\end{array}$ & $\begin{array}{l}31.70 \pm 0.48 \\
\text { Clase A }\end{array}$ & $\begin{array}{c}31.70 \pm 0.48 \\
\text { Aceptada }\end{array}$ & $\begin{array}{c}45.04 \pm 0.06 \\
\text { Aceptada }\end{array}$ & $\begin{array}{c}83.70 \pm 0.82 \\
\text { Aceptada }\end{array}$ & $\begin{array}{c}1.0334 \pm 0.01 \\
\text { Aceptada }\end{array}$ \\
\hline MC & $\begin{array}{c}32.46 \pm 1.86 \\
\text { Clase } A\end{array}$ & $\begin{array}{l}29.27 \pm 0.36 * \\
\text { Clase C }\end{array}$ & $\begin{array}{c}23.01 \pm 3.28 * \\
\text { Rechazada }\end{array}$ & $\begin{array}{c}35.39 \pm 4.56 * \\
\text { Rechazada }\end{array}$ & $\begin{array}{c}80.20 \pm 1.31 \\
\text { Rechazada }\end{array}$ & $\begin{array}{c}1.0334 \pm 0.01 \\
\text { Aceptada }\end{array}$ \\
\hline MP & $\begin{array}{c}32.77 \pm 2.98 \\
\text { Clase A }\end{array}$ & $\begin{array}{l}30.04 \pm 0.42 \\
\text { Clase B }\end{array}$ & $\begin{array}{c}23.79 \pm 1.50 \\
\text { Rechazada }\end{array}$ & $\begin{array}{c}39.88 \pm 1.69 \\
\text { Rechazada }\end{array}$ & $\begin{array}{c}80.40 \pm 2.94 \\
\text { Rechazada }\end{array}$ & $\begin{array}{c}1.0302 \pm 0.02 \\
\text { Aceptada }\end{array}$ \\
\hline MT & $\begin{array}{c}31.55 \pm 0.68 * \\
\text { Clase B }\end{array}$ & $\begin{array}{c}31.17 \pm 0.16 \\
\text { Clase } A\end{array}$ & $\begin{array}{c}23.75 \pm 1.46 \\
\text { Rechazada }\end{array}$ & $\begin{array}{c}42.06 \pm 1.49 \\
\text { Rechazada }\end{array}$ & $\begin{array}{c}79.80 \pm 2.98 * \\
\text { Rechazada }\end{array}$ & $\begin{array}{c}1.0311 \pm 0.01 \\
\text { Aceptada }\end{array}$ \\
\hline
\end{tabular}

Est: establecimiento, GB: grasa butírica, PT: proteínas totales, Cas: caseína, Lac: lactosa, SNG: sólidos no grasos, Den: densidad, EF: establo familiar, MC: Mercado Campesino, MP: Mercado Pino Suárez, MT: Mercado Tamulté. *Indica diferencia estadística significativa $(p<0.05)$. 
Con base en los criterios normativos mexicanos del Consejo para el fomento de la calidad de la leche y sus derivados, A.C., la calidad microbiológica de las muestras analizadas, se puede clasificar como "Aprobada" o "No aprobada", de acuerdo a los parámetros de acidez titulable, prueba de alcohol, materia extraña e inhibidores bacterianos. De acuerdo al número de bacterias mesofílicas aerobias (BMA) y al conteo de CS, se clasifica en "Clase 1, 2, 3 o 4", siendo la Clase 1 la máxima calidad. Por último, de acuerdo con la prueba de reductasa se clasifica como "Buena", "Regular" o "Mala".
Las muestras analizadas provenientes del EF obtuvieron la mejor clasificación de calidad microbiológica. Esto debido a que, de acuerdo con la acidez titulable, prueba de alcohol, materia extraña e inhibidores bacterianos se ubicó como "Aprobada". Por el conteo de BMA y el conteo de CS, fue evaluada en "Clase 1", y de acuerdo con la evaluación de reductasa fue calificada como "Buena". Sin embargo, la leche evaluada en los tres mercados se consideró como de "Rechazo", debido a que, por la acidez titulable, prueba de alcohol, materia extraña e inhibidores bacterianos fue calificada como "No aprobada"; por la prueba de reductasa fue "Mala" y por el conteo de CS fue de "Clase 2" (Tabla 2).

Tabla 2. Evaluación de la calidad microbiológica de leche obtenida de un establo familiar y de tres mercados públicos en el estado de Tabasco.

\begin{tabular}{|c|c|c|c|c|c|c|c|}
\hline \multirow[b]{2}{*}{ Est } & \multicolumn{7}{|c|}{ Parámetros y evaluación de la calidad microbiológica de leche } \\
\hline & AT $\mathbf{g} / \mathbf{L}$ & PA & ME & IB & BMA UFC/mL & CS CS/mL & $\begin{array}{c}\text { RE } \\
\text { Bacterias/mL }\end{array}$ \\
\hline $\mathrm{EF}$ & $\begin{array}{c}1.45 \pm 0.05 \\
\text { Aprobada }\end{array}$ & $\begin{array}{l}\text { Negativo } \\
\text { Aprobada }\end{array}$ & $\begin{array}{c}\text { Libre } \\
\text { Aprobada }\end{array}$ & $\begin{array}{l}\text { Negativo } \\
\text { Aprobada }\end{array}$ & $\begin{array}{c}20500 \pm 6476.45 \\
\text { Clase } 1\end{array}$ & $\begin{array}{c}28985 \pm 2568.18 \\
\text { Clase } 1\end{array}$ & $\begin{array}{c}5 \text { horas: } \\
100000 \text { a } 200000 \\
\text { Buena }\end{array}$ \\
\hline MC & $\begin{array}{l}1.80 \pm 0.8^{*} \\
\text { No aprobada }\end{array}$ & $\begin{array}{l}\text { Positivo } \\
\text { No Aprobada }\end{array}$ & $\begin{array}{l}\text { Presencia } \\
\text { No Aprobada }\end{array}$ & $\begin{array}{l}\text { Positivo } \\
\text { No Aprobada }\end{array}$ & $\begin{array}{c}106.287 \pm 5.308 \\
* \\
\text { Clase } 2\end{array}$ & $\begin{array}{c}77.345 \pm 2.938 \\
\text { Clase } 2\end{array}$ & $\begin{array}{c}<2 \text { horas: } \\
2 \text { a } 10 \text { millones } \\
\text { Mala }\end{array}$ \\
\hline MP & $\begin{array}{l}1.78 \pm 0.2 \\
\text { No aprobada }\end{array}$ & $\begin{array}{c}\text { Positivo } \\
\text { No Aprobada }\end{array}$ & $\begin{array}{l}\text { Presencia } \\
\text { No Aprobada }\end{array}$ & $\begin{array}{l}\text { Positivo } \\
\text { No Aprobada }\end{array}$ & $\begin{array}{c}104.928 \pm 5.564 \\
\text { Clase } 2\end{array}$ & $\begin{array}{c}79.528 \pm 2.793 * \\
\text { Clase } 2\end{array}$ & $\begin{array}{c}\text { < } 2 \text { horas: } \\
2 \text { a } 10 \text { millones } \\
\text { Mala }\end{array}$ \\
\hline MT & $\begin{array}{l}1.76 \pm 2.4 \\
\text { No aprobada }\end{array}$ & $\begin{array}{l}\text { Positivo } \\
\text { No Aprobada }\end{array}$ & $\begin{array}{c}\text { Presencia } \\
\text { No Aprobada }\end{array}$ & $\begin{array}{l}\text { Positivo } \\
\text { No Aprobada }\end{array}$ & $\begin{array}{c}104.007 \pm 5.390 \\
\text { Clase } 2\end{array}$ & $\begin{array}{c}78.610 \pm 1.340 \\
\text { Clase } 2\end{array}$ & $\begin{array}{c}<2 \text { horas: } \\
2 \text { a } 10 \text { millones } \\
\text { Mala }\end{array}$ \\
\hline
\end{tabular}

Est: establecimiento, AT: acidez titulable, PA: prueba de alcohol, ME: materia extraña, IB: inhibidores bacterianos, BMA: bacterias mesofílicas aerobias, CS: células somáticas, RE: reductasa, EF: establo familiar, MC: Mercado Campesino, MP: Mercado Pino Suárez, MT: Mercado Tamulté. *Indica diferencia estadística significativa $(p<0.05)$.

\section{DISCUSIÓN}

Siendo la leche de vaca un alimento básico para el ser humano y, por su alto contenido de grasa y proteínas, una materia prima que permite el procesamiento de diversas gamas de productos manufacturados utilizados en la alimentación humana (3). Se requiere de su máxima calidad para que cumpla dichos propósitos, sin embargo, la calidad y aceptación del producto pueden verse severamente afectadas por prácticas inadecuadas de higiene durante todo el proceso de obtención: pre-ordeño, ordeño y post-ordeño.

La calidad nutricional de las muestras de leche analizadas provenientes del EF, en el presente estudio, fueron clasificadas dentro de los valores considerados como aceptables para leche cruda de vaca, acorde con los parámetros regulados por los criterios normativos mexicanos que establece el Consejo para el fomento de la calidad de la leche y sus derivados, A.C. Se apreciaron valores de proteína y caseína que la colocaron como leche de clase $A(\geq 31 \mathrm{~g} / \mathrm{L})$. Lo que coincide con lo reportado en otra investigación con valores de proteína similares $(32.94 \mathrm{~g} / \mathrm{L}$ ) en muestras de leche bovina analizadas durante los mismos meses que los obtenidos en la presente investigación. Por el contrario, en las muestras de leche adquiridas en los mercados públicos, los valores de caseína no llegaron al rango mínimo, lo cual probablemente pueda ser atribuido a una mayor frecuencia de mastitis subclínica, así como una higiene deficiente en el ordeño (10).

Esto hace suponer que la disminución de valores de caseína podría corresponder con el aumento de proteínas séricas, consecuencia de un alto conteo somático que genera enzimas proteolíticas y provoca disminución en el contenido de caseína (11). 
El conteo de BMA (>10000 ufc/mL) y de CS, son medidas de las condiciones de higiene en la producción de la leche, pueden afectar la calidad y aceptación del producto lácteo por el consumidor (12). El conteo bacteriano del 100 $\%$ de las muestras provenientes de los mercados públicos evaluados, presentan una mala calidad microbiológica ya que sobre pasan el límite permitido de unidades formadoras de colonia y de CS, de acuerdo a los criterios normativos mexicanos del Consejo para el fomento de la calidad de la leche y sus derivados, A.C., en donde se establece el conteo total de bacterias mesofílicas aerobias deseables $\leq 100000$ UFC/ $\mathrm{mL}$ y el conteo de $\mathrm{CS} \leq 400000 \mathrm{CS} / \mathrm{mL}$, lo que implica la no aceptabilidad de dicho producto para el consumo humano.

Por el contrario, la leche evaluada en el EF reporta valores muy bajos, incluso menores a los reportados en una región al sur de la ciudad de México, durante los mismos meses evaluados en el presente estudio (10), pero a la vez similares con otra investigación en el estado de Morelos, referentes a calidad sanitaria de leche de vaca (12), ambos trabajos realizados durante los mismos meses del presente estudio, pero en diferentes zonas de México. Esto permite enfatizar la importancia del uso de adecuadas instalaciones, prácticas de higiene y manejo de la ordeña, así como el conocimiento de la procedencia de la leche que se encuentra a la venta.

Existe evidencia que en la época de nortes las células somáticas pueden elevarse, e incluso se correlacionan con la presencia de E. coli, lo cual se atribuye a una inadecuada limpieza de la ubre y del equipo de ordeño (13). Esto es corroborado, al reportar conteos ideales de CS en muestras de leche procedente de establos con manejo adecuado de higiene en el proceso de la ordeña y el establecimiento, incluso en época de invierno y de nortes (14), tal como se reporta en el presente estudio, para las muestras del EF; no así para las que se reportaron en los tres mercados públicos.

Otro microrganismo patógeno de interés, presente en la leche y productos lácteos debido a una higiene deficiente en el manejo de la ordeña, es el Staphylococcus aureus, ya que es causa de mastitis bovina y produce costos elevados en la industria láctea (15). Aunque el tratamiento de elección para este padecimiento es el uso de antibióticos (principalmente penicilinas, cefalosporinas, entre otras), en la actualidad, existe la tendencia de un enfoque preventivo basado en adecuadas prácticas de higiene a lo largo de todo el proceso de la ordeña (16). Además, las vacas con mastitis subclínica son consideradas un reservorio para este peligro que causa la contaminación del producto lácteo a lo largo de toda la cadena de producción (10).

Entre los factores que influyen en un alto conteo de CS y BMA, se contempla la ausencia de higiene en la rutina del ordeño, el mal funcionamiento del equipo, mal manejo de los desinfectantes y selladores, la no identificación del agente infeccioso $y$, finalmente, la efectividad de las medidas de control y los tratamientos. Estas causas multifactoriales se pueden controlar cuando al interior de los establos familiares se cuenta con procedimientos claros, se capacita correctamente al personal y existe un plan de seguimiento estricto en los procesos (9).

En conclusión, con respecto a los criterios normativos mexicanos del Consejo para el fomento de la calidad de la leche y sus derivados, A.C., la evaluación físico-química y microbiológica de la leche producida en el establo familiar ubicado en el sureste mexicano, colocan esta producción de leche en clase $A$. Las muestras de leche evaluadas en los tres mercados públicos registraron leche de rechazo, e incluso con parámetros fuera del mínimo permitido, lo que con lleva a ser leche no apta para el consumo humano ni para elaboración de subproductos.

Se recomienda llevar a cabo un estudio de la calidad de leche cruda de vaca durante las diferentes estaciones del año y en diferentes sistemas de producción.

\section{Conflicto de intereses}

Los autores del presente trabajo declaramos que no existe conflicto de intereses.

\section{Agradecimientos}

Al Lic. Antonio Peralta García propietario del rancho San Carmen, por el apoyo otorgado para la realización del estudio. 


\section{REFERENCIAS}

1 Motta-Delgado PA, Rivera MS, Duque JA, Guevara FA. Factores inherentes a la calidad de la leche en la agroindustria alimentaria. Rev Colombiana Cienc Anim RECIA. 2014; 6(1):223-242. https://doi.org/10.24188/ recia.v6.n1.2014.265

2. Frétin $M$, Martin $B$, Buchin $S$, Desserre $B$, Lavigne $\mathrm{R}$, Tixier $\mathrm{E}$, et al. Milk fat composition modifies the texture and appearance of Cantal-type cheeses but not their flavor. J Dairy Sci. 2018; 102:1131-1143. https://doi. org/10.3168/jds.2018-15534

3. Ocampo R, Gómez C, Restrepo D, Cardona $\mathrm{H}$. Comparative study of compositional and nutritional parameters in cow, goat and buffalo milk, Antioquia, Colombia. Rev Colombiana Cienc Anim RECIA. 2016; 8(2):177-186. https://doi.org/10.24188/ recia.v8.n2.2016.185

4. Bautista-Romero J, Contreras-Rodríguez U, Martínez-Luna G. Cow-free milk: a sustainable production alternative from fermentation. RD ICUAP. 2020; 6(1):201-215. http:// www.apps.buap.mx/ojs3/index.php/rdicuap/ article/view/1747

5. Aguilar-Pérez CF, Ku-Vera JC, Magaña-Monforte JG. Energetic efficiency of milk synthesis in dual-purpose cows grazing tropical pastures. Trop Anim Health Prod. 2011; 43:767-772. https://doi.org/10.1007/s11250-010-9714-z

6. Brousett-Minaya $M$, Torres-Jiménez $A$, ChambiRodríguez A, Mamani-Villalba B, HernánGutiérrez S. Physicochemical, microbiological and toxicological quality of raw milk in cattle basins of the region Puno-Peru. Sci Agropecu. 2015; 6(3):165-176. http://dx.doi. org/10.17268/sci.agropecu.2015.03.03

7. Ortíz M, Rosales C, Aguilar Y, Murillo Y, Serpa G, Paguay T, Coronel G. Estudio exploratorio sobre la presencia de contaminantes en leche cruda proveniente de la cuenca lechera del Tarqui de la Sierra Sur Ecuatoriana. Maskana. 2017; 8(1):121-127. https://doi. org/10.18537/mskn.08.01.11

8. Ishag KHM. Risk Analysis of Investments In-Milk Collection Centers. Sustain Agric Res. 2015; 4(2):104-115. https://doi. org/10.5539/sar.v4n2p104
9. Bonifaz García N, Requelme NJ. Buenas prácticas de Ordeño y la Calidad higiénica de la Leche en el Ecuador. Revista de Ciencias de la Vida. 2011; 14(2):45-57. https://doi. org/10.17163/lgr.n14.2011.04

10. Álvarez-Fuentes G, Herrera-Haro JG, AlonsoBastida G, Barreras-Serrano A. Calidad de la leche cruda en unidades de producción familiar del sur de Ciudad de México. Arch Med Vet. 2012; 44(3):237-242. http://dx.doi. org/10.4067/S0301-732X2012000300005

11. Cerón-Muñoz MF, Agudelo EJ, MaldonadoEstrada JG. Relación entre el recuento de células somáticas individual o en tanque de leche y la prueba CMT en dos hatos lecheros del departamento de Antioquia (Colombia). Rev Col Cienc Pec 2007; 20:472-483. https:// revistas.udea.edu.co/index.php/rccp/article/ view/324204/20781376

12. Ávila-Téllez $S$, Gutiérrez-Chávez AJ, SánchezGómez JI, Canizal-Jiménez E. Comparación del estado de salud de la ubre y la calidad sanitaria de la leche de vacas ordeñadas manual o mecánicamente. Vet Méx. 2002; 33(4):387-394. https://doi.org/10.21753/ vmoa.33.004.79

13. Fröberg $S$, Aspegren-Güldorff $A$, Olsson I, Marin B, Berg C, Hernández C, et al. Effect of restricted suckling on milk yield, milk composition and udder health in cows and behaviour and weight gain in calves, in dual-purpose cattle in the tropics. Trop Anim Health Prod. 2007; 39(1):71-81. https://doi. org/10.1007/s11250-006-4418-0

14. Dufour S, Dohoo IR, Barkema HW, Descôteaux $\mathrm{L}$, Devries TJ, Reyher KK, et al. Manageable risk factors associated with the lactational incidence, elimination, and prevalence of Staphylococcus aureus intramammary infections in dairy cows. J Dairy Sci. 2012; 95(3):1283-1300. https://doi.org/10.3168/ jds.2011-4711

15. De Briyne N, Atkinson J, Borriello SP, Pokludová L. Antibiotics used most commonly to treat animals in Europe. Vet Rec. 2014; 175(13):325. http://dx.doi.org/10.1136/vr.102462

16. Kümmel J, Stessl B, Gonano M, Walcher G, Bereuter O, Fricker M, et al. Staphylococcus aureus entrance into the dairy chain: tracking S. aureus from dairy cow to cheese. Front Microbiol. 2016; 7:1603. https://doi. org/10.3389/fmicb.2016.01603 